\title{
Correction to: Transmission Cycle of SARS-CoV and SARS-CoV-2
}

\author{
Tushar Yadav and Shailendra K. Saxena (D)
}

\section{Correction to:}

\section{Chapter 4 in: S. K. Saxena (ed.), Coronavirus Disease 2019 (COVID-19), Medical Virology: from Pathogenesis to Disease Control, https://doi.org/10.1007/978-981-15-4814-7_4}

The published version in Figure 4.1 has been withdrawn in Chapter 4 due to absence of permission to reuse. The corrected figure includes a "redrawn" image.

? Unknown routes of Cross-species

Transmission: Food borne/ Close contact

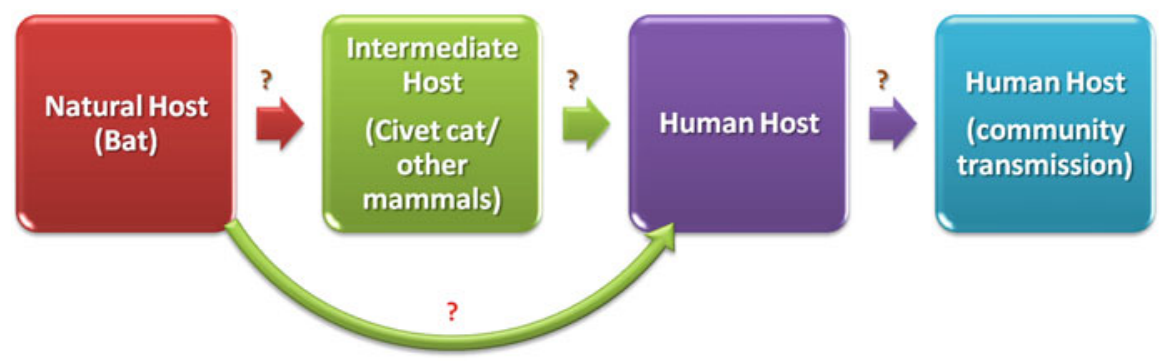

Fig. 4.1 The probable transmission path of SARS-CoV and SARS-CoV-2 from natural hosts to various hosts

The updated online version of this chapter can be found at https://doi.org/10.1007/978-981-15-4814-7_4

(C) The Editor(s) (if applicable) and The Author(s), under exclusive licence to C1 Springer Nature Singapore Pte Ltd. 2020

S. K. Saxena (ed.), Coronavirus Disease 2019 (COVID-19), Medical Virology: from

Pathogenesis to Disease Control, https://doi.org/10.1007/978-981-15-4814-7_17 